\title{
Graphite Morphology's Influence on Shot Peening Results in Cast Irons
}

\author{
Mattias Lundberg ${ }^{1, a}$, Ru Lin Peng ${ }^{1, b}$, Maqsood Ahmad ${ }^{2, c}$, Daniel Bäckström ${ }^{3, d}$, \\ Taina Vuoristo ${ }^{3, \mathrm{e}}$, Sten Johansson ${ }^{1, \mathrm{f}}$ \\ ${ }^{1}$ Department of Management and Engineering, Linköping University, SE-58183 Linköping, Sweden \\ ${ }^{2}$ Base Engine \& Materials Technology, Volvo Powertrain, SE-40508 Gothenburg, Sweden \\ ${ }^{3}$ Testing Methods and Testing, Scania CV AB, SE-15187 Södertälje, Sweden \\ amattias.lundberg@liu.se, ${ }^{\mathrm{b}}$ ru.peng@liu.se, ${ }^{\mathrm{C}}$ maqsood.ahmad@volvo.com, \\ dDaniel.Backstrom@scania.com, ${ }^{\mathrm{e}}$ taina.vuoristo@scania.com, 'sten.johansson@liu.se
}

Keywords: shot peening, cast iron, graphite morphology, EBSD, residual stress

\begin{abstract}
The different shot peening responds of a grey cast iron (GI) with its flake graphite and a compacted cast iron (CGI) with its vermicular graphite was analyzed and compared in this paper. For peening using identical parameters, CGI showed a larger plastic deformation zone with higher subsurface compressive stresses than GI. Electron backscatter diffraction (EBSD) mapping and backscatter electron imaging revealed that plastic deformation of the matrix near graphite inclusions is affected by the size and geometry of the graphite. The different behaviors of graphite are explained by their capability to damp mechanical force but at the same time to cause stress concentration in the matrix. The better shot peening results for CGI may be attributed to a lower damping effect of its graphite inclusions and capability of the matrix for larger plastic deformation.
\end{abstract}

\section{Introduction}

The understanding of the graphite's role together with the matrix on the mechanical and physical properties of cast irons is still today very limited. There is no doubt that the mechanical behaviour of cast irons is a cooperative action between the matrix (ferritic, pearlitic or ferritic/pearlitic) and the graphite (flake, vermicular, mellable or nodular) under loading. The shape, amount and distribution of the graphite inclusions all affect the property of the casting [1]. For example, due to a reduced notch effect, nodular graphite iron in general has better mechanical properties (e.g. yield strength, elongation, fatigue strength, Young's modulus) than vermicular graphite iron which in turn has better mechanical properties than flake graphite iron [2,3].

The graphite in cast irons also absorbs mechanical energy by sliding between their basal planes. The damping effect therefore depends on the morphology and amount of graphite [4,5], and the different types of cast irons may respond differently to shot peening. When the shots interact with the surface, high level of local, plastic deformation occurs, leading to generation of compressive residual stresses in a surface layer. The residual stress field and the deformation zone depend not only on the shot peening parameters but also the peened material. While the limited literature available in this field mostly deals with shot peening of nodular graphite cast irons [6,7], little work can be found on shot peening flake and vermicular cast irons and the influence of graphite morphology on the shot peening result.

In the current project, we investigate the responds of two cast irons of pearlitic matrix, a grey iron (GI) with flake graphite and a compacted graphite iron (CGI) with vermicular graphite, to shot peening. The ultimate goal of the project is to improve the fatigue strength of the two cast irons through optimising residual stresses. X-ray diffraction measurements revealed that a significant peening affected zone could be induced by peening operations that had been selected based on the limited publications found in the literature. For the same shot peening conditions there were distinctive differences between the two cast irons. Better shot peening results with a larger compression zone were achieved in the CGI. The depth of plastic deformation, indicated by the 
diffraction peak width, also differed somewhat between the two materials. While the X-ray diffraction analysis was dealt with in a parallel paper published in the current volumes [8], this article focuses on electron microscopy studies of several shot peened samples to understand the microstructural influence on the shot peening results. By electron backscatter diffraction (EBSD) and electron channeling contrast imaging (ECCI), changes in the peening affected zone of GI and CGI samples peened using identical peening parameters were analyzed.

\section{Experimental Details}

Materials and shot peening. The nominal chemical compositions of the GI and the CGI are given in Table 1. Microstructure characterization presented in Fig. 1 reveals different graphite morphology and matrix between the two materials. While the GI exhibits more densely populated flaky graphite, the CGI has somewhat fewer but thicker vermicular graphite and a small amount of nodular graphite. In addition, the graphite volume fraction is slightly lower, $11.0 \%$ in the GI against $12.7 \%$ in the CGI. The matrix in GI is fully pearlitic with lamellar ferrite and cementite. Electron channeling contrast imaging (Fig.1(c)) and EBSP mapping (Fig.1(e)) reveal a high density of low angle grain boundaries (LAGBs) which are often associated with boundaries of pearlitic colonies. In the current paper, a misorientation (orientation difference between two neighbouring measurement points) of $1.5^{\circ}$ to $10^{\circ}$ is defined as LAGB and over $10^{\circ}$ as High Angle Grain Boundary (HAGB). In contrast, larger pearlitic lamellae and a low LAGB density (Figs.1(d) and (f)) were observed in the CGI. In addition, a small amount of ferritic grains was found embedded either between pearlitic colonies or at the pearlite-graphite interface.

The nominal mechanical properties, namely the Young's modulus, yield stress, tensile strength, and ductility are given in Table 2. The matrix Vickers hardness, averaged over measurements in the centre of 20 randomly chosen but large matrix areas, is $298 \pm 20$ for GI and $296 \pm 45$ for CGI. The larger scatter found with the latter is attributed to soft ferrite grains scattered in the matrix.

Cylindrical samples of $\Phi 30 \mathrm{~mm} \times 9 \mathrm{~mm}$ were machined from castings that had been annealed to reduce thermal residual stresses. The end surface to be shot peened was mechanically polished to minimize the influence of machining. Table 3 lists the shot peening variables. Steels shots hardened to a hardness of HRC56 were used.

Table 1 Nominal chemical compositions of the cast irons (wt.\%)

\begin{tabular}{|l|c|c|c|c|c|c|c|c|c|}
\hline & $\mathrm{C}$ & $\mathrm{Si}$ & $\mathrm{Mn}$ & $\mathrm{P}$ & $\mathrm{S}$ & $\mathrm{Cu}$ & $\mathrm{Cr}$ & $\mathrm{Mo}$ & $\mathrm{Fe}$ \\
\hline Grey iron & 3.15 & 1.8 & 0.65 & $\mathrm{Max} 0.08$ & 0.12 & 0.90 & 0.14 & 0.25 & Bal. \\
\hline Compacted graphite iron & 3.8 & 2.0 & 0.20 & Max 0.05 & 0.01 & 0.90 & 0.02 & 0.005 & Bal. \\
\hline
\end{tabular}

Table 2 Nominal mechanical properties (tensile test) of the grey and compacted graphite cast irons

\begin{tabular}{|c|c|c|c|c|c|}
\hline Material & $\begin{array}{c}\text { Young's modulus } \\
(\mathrm{GPa})\end{array}$ & $\begin{array}{c}\text { Rp0,2 } \\
(\mathrm{MPa})\end{array}$ & $\begin{array}{c}\mathrm{Rm} \\
(\mathrm{MPa})\end{array}$ & $\begin{array}{c}\text { Elongation } \\
(\%)\end{array}$ & $\begin{array}{c}\text { Matrix hardness } \\
(\mathrm{HV})\end{array}$ \\
\hline GI & $105-125$ & 260 & 290 & $0.6-0.7$ & $298 \pm 20$ \\
\hline CGI & $140-150$ & 280 & 400 & $>=1-3.5$ & $296 \pm 45$ \\
\hline
\end{tabular}

Table 3 Shot peening parameters

\begin{tabular}{|c|c|c|c|c|c|}
\hline Sample & $\begin{array}{l}\text { Peening } \\
\text { process }\end{array}$ & $\begin{array}{c}\text { Shot size, } \Phi \\
(\mathrm{mm})\end{array}$ & $\begin{array}{l}\text { Intensity } \\
\text { Almen }\end{array}$ & Coverage $(\%)$ & $\begin{array}{c}\text { Surface } \\
\text { roughness (Ra) }\end{array}$ \\
\hline GI2 & \multirow[b]{2}{*}{2} & \multirow[b]{2}{*}{$0.43(\mathrm{~S} 170)$} & \multirow[b]{2}{*}{$0.17 \mathrm{mmA}$} & \multirow[b]{2}{*}{100} & 2.32 \\
\hline CGI2 & & & & & 2.61 \\
\hline GI5 & \multirow[b]{2}{*}{5} & \multirow[b]{2}{*}{$0.43(\mathrm{~S} 170)$} & \multirow[b]{2}{*}{$0.37 \mathrm{mmA}$} & \multirow[b]{2}{*}{100} & 5.43 \\
\hline CGI5 & & & & & 5.99 \\
\hline
\end{tabular}



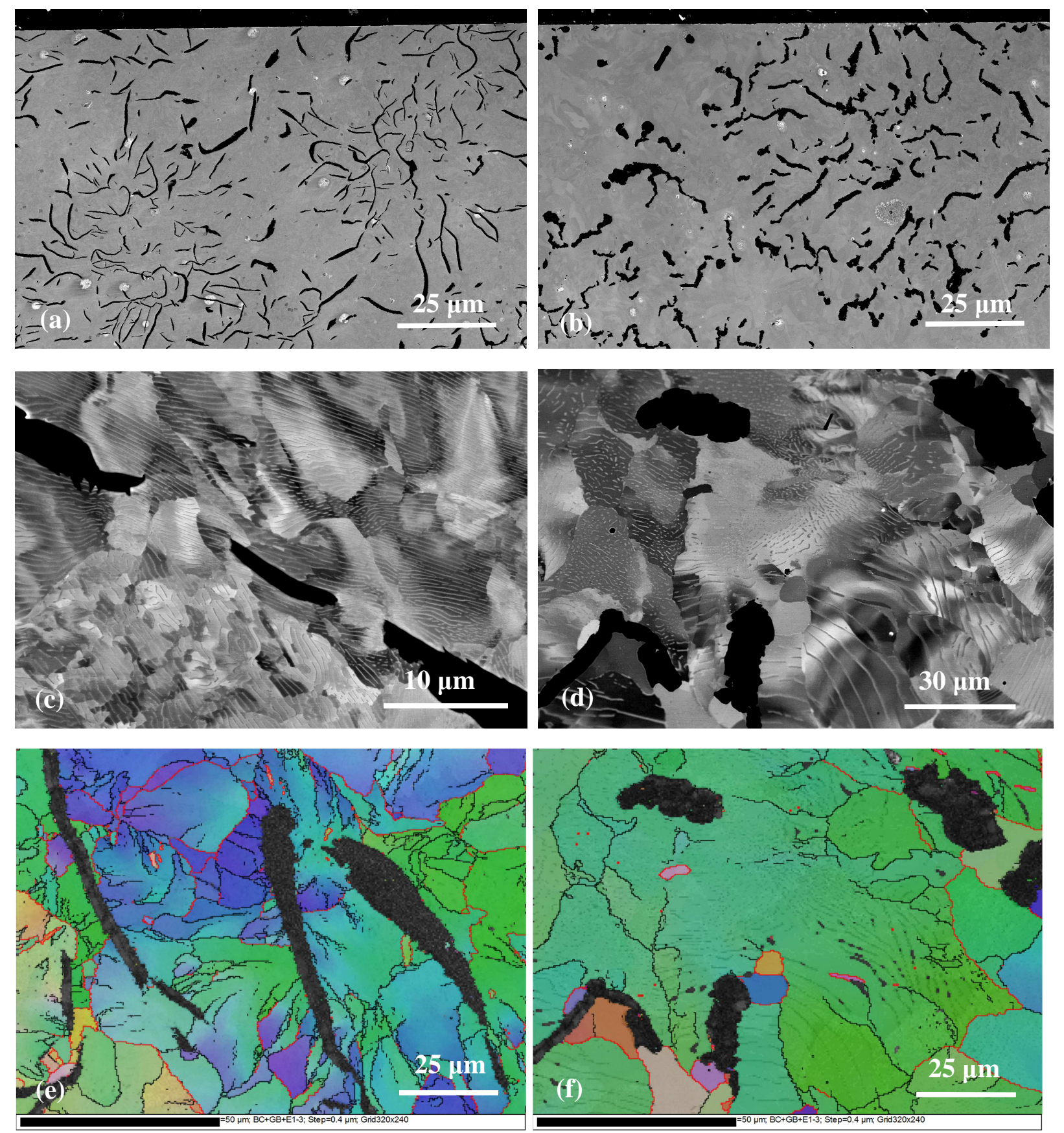

Fig.1 Microstructure of GI ((a), (c) and (d)) and CGI ((b), (d) and (f)). (c) and (d) are ECCI images and (e) and (f) are EBSD images.

Experiments. The magnitude and distribution of residual stresses have been investigated with xray diffraction (XRD). For the experimental details, see [8].

Microstructural changes in the peening affected depth were studied in a Hitachi SU-70 FESEM scanning microscope. Samples shot peened with identical peening parameters as those for XRD study were sectioned through a diameter. The cutting surfaces were then mechanically ground and polished, following the procedure for preparing metallographic samples for EBSD measurements. Annular solid state backscatter detectors from Hitachi were used for electron channelling contrast imaging and a Nordley detector from Oxford Instrument and Channel 5 software were used for EBSD mapping of the ferritic phase.

\section{Results and Discussion}

Residual stress distribution. Results from XRD diffraction measurements on the shot peened samples are compared in Fig. 2. Significant compressive residual stresses are observed in the 
surface and subsurface. Increasing peening intensity from 0.17 to $0.37 \mathrm{mmA}$ expands the compression zone but reduces the surface compressive stresses. There is a distinct difference between the two cast irons. For both peening conditions, while the surface residual stresses are similar, subsurface compressive residual stresses are larger in CGI than in GI. Plastic deformation leads to diffraction peak broadening. Therefore as a qualitative measure of plastic deformation the depth profiles of Full Width at Half Maximum diffraction peak intensity (FWHM) are also plotted in Fig. 2. As can be seen, the FWHM distributions are similar for both cast irons. However, since the diffraction peak width of the CGI without shot peening effect is somewhat lower, it can be derived that the degree of peening induced deformation is somewhat larger in the CGI, which results in larger compressive residual stresses in the peening affected depth.
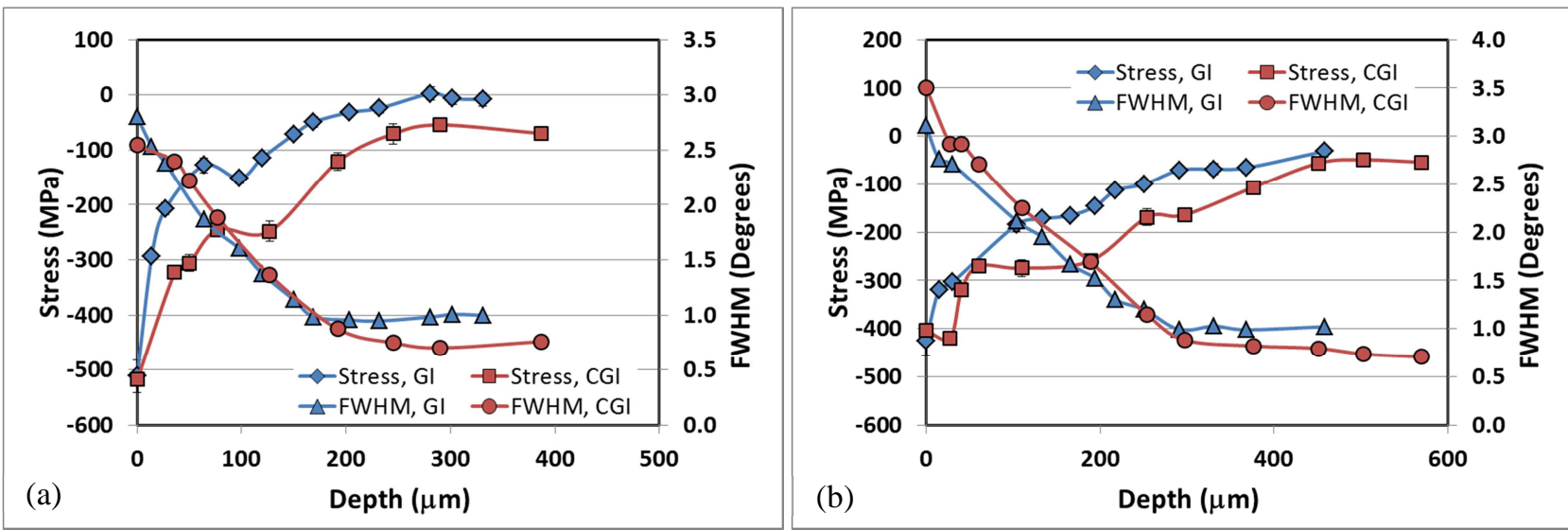

Fig. 2 Residual stress and FWHM profiles for peening process 2 (a) and process 5 (b).

Deformation in the peening affected depth. Surface roughness due to shot peening is given in Table 3 as Ra. Increasing peening intensity gives a rougher surface. However, the difference between the two materials is marginal. Surface and subsurface microcracks are rare for low intensity peening but become more common when the peening intensity is increased. They are often associated with graphite, at its tip or in the neck area between neighbouring graphite flakes or at non-graphite inclusions.

EBSD mapping using a fine step-size of $0.4 \mu \mathrm{m}$ was carried out on subsurface areas of the shotpeened samples. Two characteristic regions, one with elongated graphite lying parallel to the shot peened surface, see Fig. 3(a) and Fig. 5(a), and the other one with only small graphite inclusions, see Fig. 3(b) and Fig. 5(b), were examined. They are denoted as G (graphite rich) and P (pearlite rich) region, respectively. On all the EBSD maps presented below, graphite appears in dark grey, LAGBs (between $1.5^{\circ}$ and $10^{\circ}$ ) in black and HAGBs (over $10^{\circ}$ ) in red. Plastic deformation results in lattice distortion and rotation, leading to an increased concentration of LAGBs. Therefore, the distribution and density of LAGBs can provide valuable information for interpreting the interactions between the microstructure and plastic waves induced by the impingement of shots upon the surface. As can be seen in Fig. 3 for GI2 peened using process 2, a considerable amount of plastic strain was introduced in the surface which in general decreases with depth. A somewhat higher concentration of HAGBs visualized as increased density of red coloured lines is obvious in the subsurface layer of especially the $G$ region. This indicates ferrite fragmentation by plastic deformation which was observed in the backscatter image in Fig. 4. Interference of graphite inclusions with the propagation of the plastic waves can be derived from Figs. 3(a) and (b). Depending on its location and shape, a graphite inclusion can cause depletion or concentration of plastic strains. In the $\mathrm{G}$ region, the graphite flake at about $10 \mu \mathrm{m}$ below the surface does not seem to have a strong effect on the propagation of the plastic waves and the pearlitic matrix before and after the graphite in the direction of wave propagation appears to show similar LAGB distributions. However, the graphite flakes lying parallel to the peened surface at about $25 \mu \mathrm{m}$ depth effectively 
block the penetration of plastic deformation, leading to a low amount of LAGBs in the matrix beneath. Fig. 3(b) also reveals a weaker effect of short graphite inclusions.
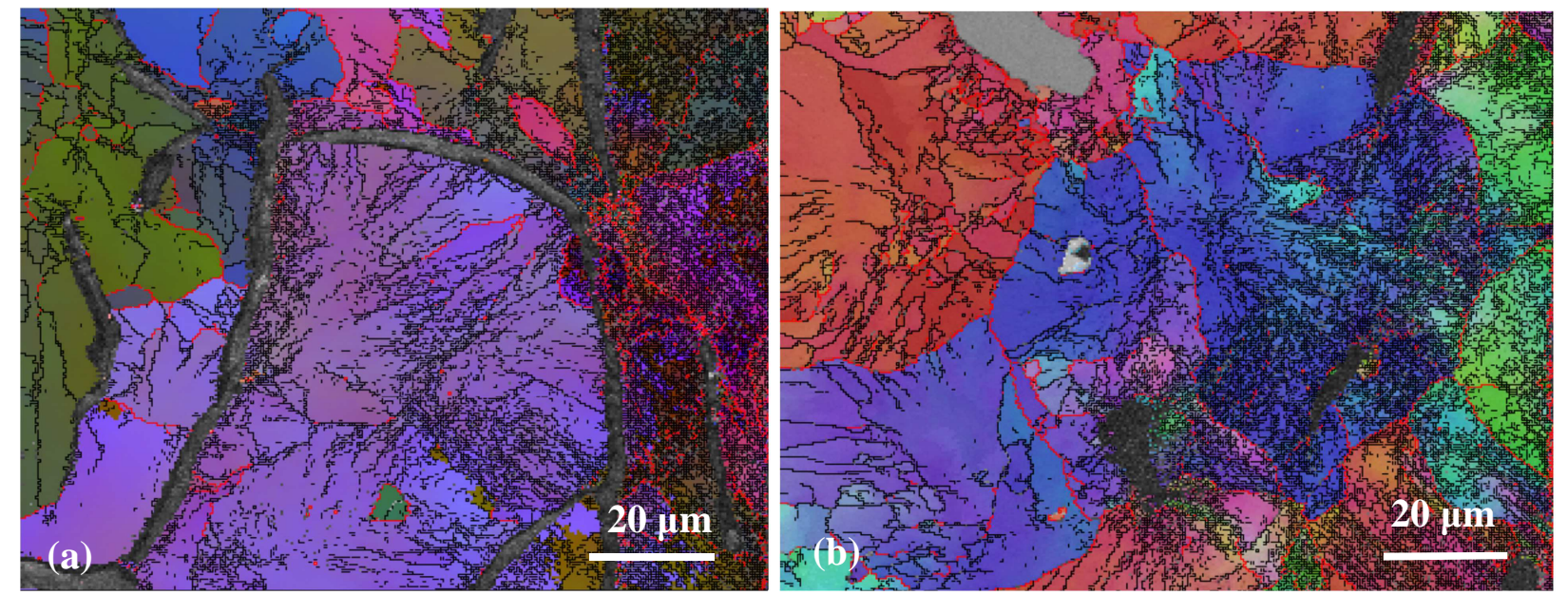

Fig. 3 EBSD maps of G (a) and P (b) regions of shot peened GI2. LAGBs in black and HAGBs in red. The shot peened surface is located on the right-hand side.



Fig. 4 ECCI image reveals plastic deformation and ferrite grain refinement beneath the peened surface and at graphite tip in the G region of GI2, shown in Fig. 3(a).

While a graphite inclusion can reduce the amount of plastic strain propagated into the depth, it can also result in local concentration of plastic strain. Because of the low strength of the graphite, its existence can lead to locally increased stress, which is caused either by a reduced effective loadcarrying area or stress concentration mechanism. A higher strain concentration is therefore often observed in the matrix associated with such graphite. Plastic strain concentration may occur around graphite closer to or far away from the peened surface, provided that the local stress is large enough to cause yielding in the matrix. While it is difficult to recognise the effect in the near surface regions where plastic deformation is severe, the influence becomes more obvious and important at greater depths where the homogenous plastic strain is relatively low or nil. Microscopic yielding at graphite tips was actually reported for tensile loading at low amplitude [9]. In GI2, increased LAGB density is observed at tips of some graphite lying located $200 \mu \mathrm{m}$ below the surface. Stress concentration at graphite can be a mechanism for the propagation of the shot peening induced plastic waves into larger depths. 

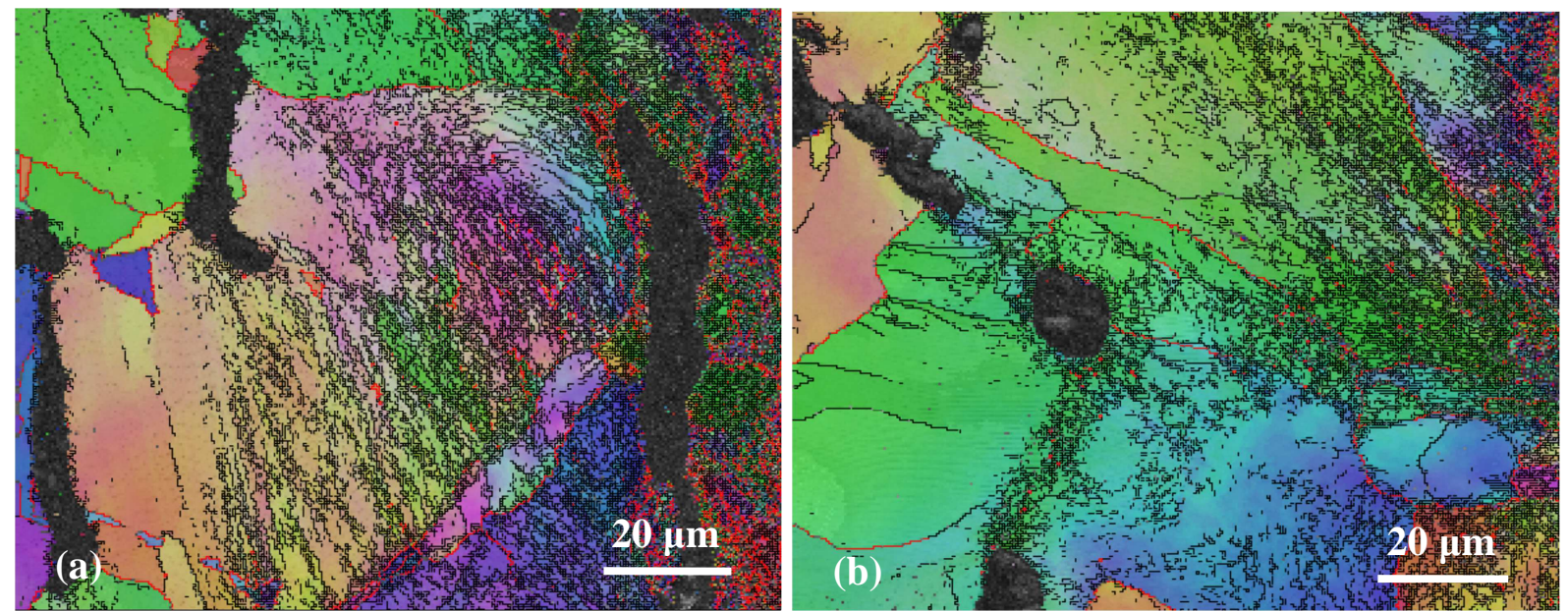

Fig. 5 EBSD maps of $\mathrm{G}$ (a) and $\mathrm{P}$ (b) regions of shot peened CGI2. LAGBs in black and HAGBs in red. The shot peened surface is located on the right-hand side.

EBSD maps of the CGI2 shot peened under the same condition as for GI2 are given in Fig. 5. The large vermicular graphite inclusion at about 20 to $30 \mu \mathrm{m}$ depth in Fig. 5(a) does not show such a strong damping effect as the flake graphite inclusion at the similar depth in the GI2 (Fig. 3(a)). A high concentration of LAGBs also appears in the matrix region below inclusions. Nodular graphite inclusions which have a low damping capability [5] seem to work more often as stress concentration raiser than as mechanical energy absorber. This is clearly seen in Fig. 5(b) and other EBSD maps for CGI5 which are not shown here. It is also interesting to note that the nodular graphite inclusion at about $80 \mu \mathrm{m}$ depth in Fig. 5(b) induces not only a high plastic strain concentration in the matrix around the graphite but also in the neck areas connecting to other graphite inclusions. ECCI shows that both the neck regions are actually boundaries between pearlitic colonies, which can be weaker than the inside of pearlitic colonies.

Images obtained from EBSD mapping of the harder peening using S170 shots and $0.37 \mathrm{mmA}$ (process 5) are not shown here. Analysis of the LAGB distributions revealed that the region of heavy plastic deformation without obvious graphite damping effect is extended to a depth of 100 $\mu \mathrm{m}$ for CGI5 and somewhat shallower for GI5. Similar effects of graphite morphology as those discussed above are found. To further explore the EBSD results, LAGBs were extracted from EBSD maps measured over a large depth and a so called LAGB density is calculated by divining the number of observed LAGBs with the total number of observations excluding void points (points that could not be indexed) at each measurement depth. The distribution of the LAGB density is proportional to the degree of plastic deformation, which can be used to compare the reaction of the CGI and GI to the shot peening. The depth distributions in GI5 and CGI5 are plotted in Fig. 6(a) for the graphite rich $\mathrm{G}$ regions and Fig. 6(b) for the P region with short graphite inclusions. Values averaged over maps obtained from un-peened GI and CGI samples are also given as references. Because of interference from the graphite inclusions, the curves oscillate and the peak in the $G$ region of CGI5 at about $150 \mu \mathrm{m}$ is related to a highly strained area between two vermicular graphite inclusions. Further, a low LAGB density is found in the surface and near surface region. This is attributed to a higher density of HAGB related to the refinement of ferrite grains by shot peening, see Fig.4. The more severe lattice distortion and rotation can also be derived from Fig. 7(a) which reveals higher LAGB angles in the surface and near surface region of both GI5 and CGI5. Similar to the LAGB density, the averaged angle of LAGB decreases with depth as the degree of plastic deformation decreases. At greater depth, the LAGBs between pearlitic grains (Fig. 1(e) and (f)) become dominant and the averaged LAGB would approach the value calculated from unpeened samples.

Fig. 6 shows that both the $\mathrm{G}$ and $\mathrm{P}$ regions of CGI5 accumulated a higher concentration of plastic strains than the corresponding regions in GI5. It can be derived from comparison of the curves that the difference can be partly attributed to the influence of graphite morphology that resulted in a larger difference in the $\mathrm{G}$ regions than in the $\mathrm{P}$ regions between the two materials. Fig. 
6(b) also discloses a different matrix plastic behaviour between the two cast irons. Although the micro hardness measurement shows essentially the same hardness (Table 2), the matrix of CGI of large pearlitic lamellae with a small amount of ferrite phase and a LAGB density has apparently a better capability for plastic deformation than GI.

Fig. 7 summarizes analyses made on 14 EBSD maps from each cast iron to cover a near surface region of about $0.65 \mathrm{~mm}$ (width) and $0.23 \mathrm{~mm}$ (depth). The deformation behaviour derived from Figs. 7 (a) and (b) agrees with that revealed by the FWHM profiles shown in Fig. 2(b). It can be concluded that as a result of different graphite inclusion and pearlitic matrix behaviours, the CGI shows a better response to the shot peening operation with a higher level of plastic deformation.
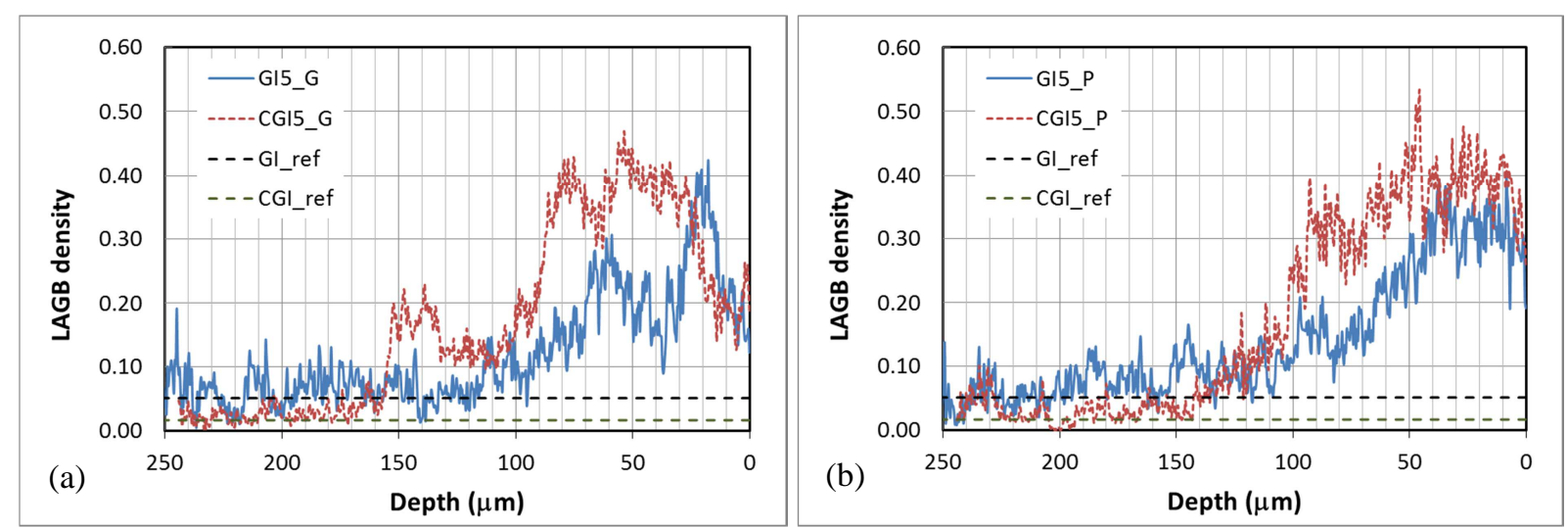

Fig. 6 Variation of LAGB density with depth in the G region (a) and P region (b) of GI5 and CGI5.
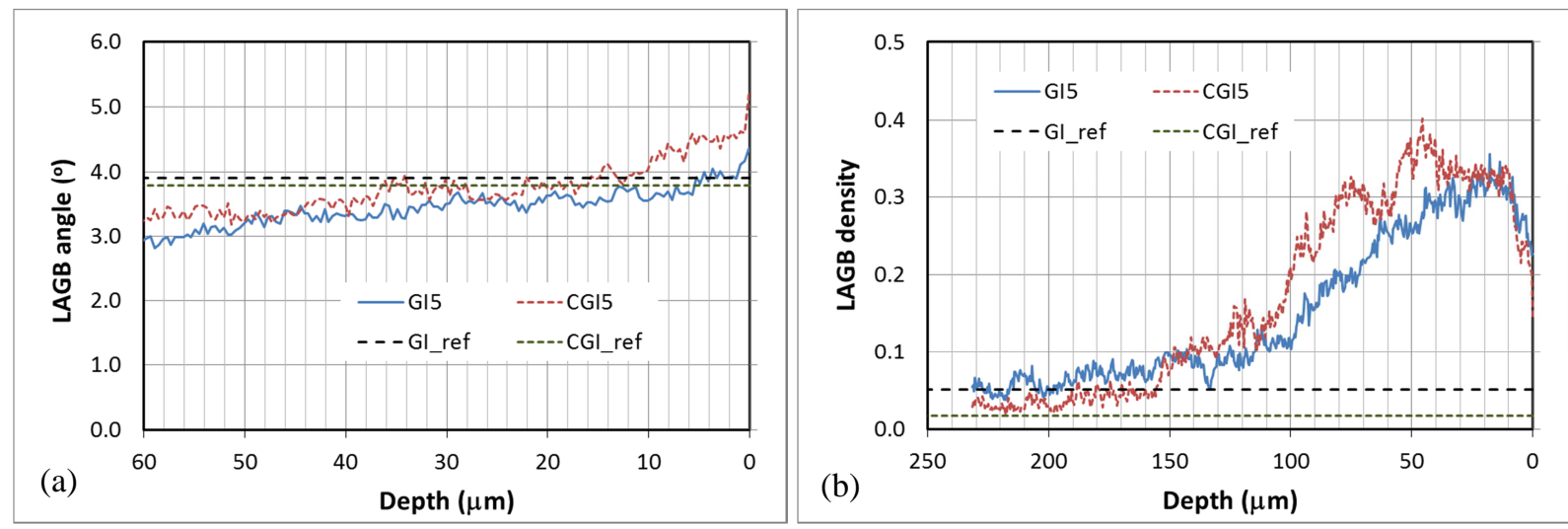

Fig. 7 Variations of average angle of LAGB with depth in the near surface region (a) and depth profiles of LAGB density (b) averaged over at least 6 EBSD maps from GI5 and CGI5.

\section{Conclusions}

Samples made of grey cast iron (GI) with flake graphite and compacted graphite cast iron (CGI) with vermicular graphite and a small amount of nodular graphite were peened to two different Almen intensities. A better responds of CGI to shot peening in the form of larger plastic deformation and compressive stresses in the subsurface was attributed to the difference in microstructure especially graphite morphologies between the two materials and different capability for plastic deformation of the matrix. The main observations are summarized below.

Flake graphite inclusions at certain depth can effectively hinder the propagation of plastic deformation into the interior of the sample.

Graphite of other morphologies, namely vermicular, nodular and short graphite inclusions do not cause a large reduction of plastic strains in the matrix.

All the observed graphite morphologies can locally raise plastic deformation in its surrounding matrix. This can lead to a deeper penetration of the plastic strain waves. 
A higher degree of plastic deformation in the pearlite dominant subsurface regions of CGI than those of GI was found and can be related to the differences in microstructure such as thickness of pearlitic lamellae and density of LAGBs.

EBSD mapping can provide useful information for analyzing interactions of the microstructure with peening induced plastic waves.

\section{Acknowledgement}

Financial supports from VINNOVA - Sweden's Innovation Agency through the program FFI Strategic Vehicle Research and Innovation, Scania CV AB and Volvo Powertrain AB are greatly appreciated. The authors are also thankful to Mrs A. Billenius for helps with sample preparations and certain experiments.

\section{References}

[1] T. Sjögren, The Influence of Graphite Morphology on the Elastic Behaviour of Cast Irons, Licentiate Thesis No 1140. (2005).

[2] Cast Irons, ASM International, Member/Customer Service Center, Materials Park, OH, 440730002, USA, 1998.

[3] S. Shao, S. Dawson, M. Lampic, The mechanical and physical properties of compacted graphite iron, Materials for Lean Weight Vehicles; Gaydon; UK; 24-25 Nov. 1997. (1997).

[4] R.D. Adams, The damping characteristics of certain steels, cast irons and other metals, J. Sound Vibrat. 23 (1972) 199-216.

[5] J.R. Dryden, G.R. Purdy, The effect of graphite on the mechanical properties of cast irons, Acta Metallurgica. 37 (1989) 1999-2006.

[6] A. Ebenau, D. Löhe, O. Vöhringer, E. Macherauch, Influence of shot peening on the microstructure and the bending fatigue strengt of bainitic-austenitic nodualr cast iron, (1990) 389398.

[7] D. Kirk, D.G. Birch, Residual stresses induced by peening austenitic ductile cast-iron, ICSP7: 7th International Conference on Shot Peening; Warsaw; Poland; 29 Sept.-1 Oct. 1999. (1999).

[8] M. Lundberg, R. Lin Peng, M. Ahmad, D. Bäckström, T. Vuoristo, S. Johansson, Influence of Shot Peening Parameters on Residual Stresses in Flake and Vermicular Cast Irons, Current volums (2013).

[9] H.T. Angus, Cast Iron--Physical and Engineering Properties, Butterworths, London and Boston.1976, 542 p. (1976). 